\title{
The Factors Influencing the Repurchasing Intention of Bank Insurance in Taiwan
}

\author{
Jie Zhu \\ Research and development center \\ Fuzhou University of International Studies and Trade
}

Fuzhou, P. R. China

\author{
Meichiao Lai \\ Logistics Department \\ Fuzhou University of International Studies and Trade \\ Fuzhou, P. R. China
}

\author{
Wuder Tsay \\ Research and development center \\ Fuzhou University of International Studies and Trade \\ Fuzhou, P. R. China
}

\begin{abstract}
This study aims to explore the factors that influencing the repurchasing intention of bank insurance in Taiwan. Data were collected from questionnaire survey, 380 questionnaires were administered, the valid sample was 330 (86.84\%). Reliability analysis, T-test, one-way ANOVA, correlation analysis and regression analysis were carried out by SPSS version19.0. The results found that there were significant correlations among corporate images of insurance company, interactive quality between banking specialists and marketing managers of insurance company, promotional activities of insurance company and repurchase intention. In the dimention of interactive quality, "attitude" of the marketing managers of insurance company ranked the highest which impacted on repurchase intention of bank insurance. There are two managerial implications. First one is to build a repurchase intention model of bank insurance for the life insurance company. The other is to provide an important reference with vocational training for marketing managers of life insurance company in Taiwan.
\end{abstract}

Keywords-bank distribution; corporate image; interactive quality; promotive activities; repurchase intention

\section{RESEARCH PURPOSE}

The purposes of the study are to explore the impact factors which influencing the repurchase intention of bank insurance, they are corporate image of insurance company, interactive quality between banking financial specialists and marketing managers of insurance company, and promotional activities of insurance company. The findings of this study will provide academic research and the life insurance company with recommendations and suggestions for future work.

\section{LiterATURE REVIEW AND RESEARCH METHOD}

An in depth case study to investigate the impcat factors of bank insurance, and to examine the relationship among them was used as the basis for this study. The case is a financial holding company's subsidiary life insurance company in Taiwan. This section first reviews the literature relevant to bank insurance. Second, repurchase intention, and its influential factors in terms of corporate image of insurance company, interactive quality between banking specialists and marketing managers of insurance company, and promotional activities of insurance company. Third, literature focuses the relationship among influential factors (independent variables) and repurchase intention (dependent variables). The operational definitions of variables are addressed as follows.

\section{A. Corporation Image ( $\mathrm{Ci})$}

Biel (1992)indicated that the brand image has three elements: the image maker (corporate image), the image of product and the brand image of competitors, all three elements influence on customers' brand image; brand image will impact on the image of the users. Gao's research (2007) pointed out the corporate image is composed of store image, product image, service image and price image. Martin Brown (1990) figured out that corporate image contains cognitive performance, cognitive value, the social image, business trust and brand identity. This research integrated the three researchers 'findings, and draw up the three measurement dimentions of corporate image in terms of "Brand identity (Bi)", "Store image ( $\mathrm{Si})$ " and "Business trust (Bt)".

\section{B. Interactive Quality $(Q a)$}

Zhan. Zhenyi (2003) believed that "interactive quality" means the extent of interaction between the customers and the service sales during the service process; Zhuo Boyan (2008) defined the interactive quality as the service attitude and professional level of service personnel. In this study, the interactive quality was defined as the quality of the interaction between the bank specialist and the marketing manager of insurance company during the service process. This study focused on the interactive quality between the marketing managers and the bank specialists in the insurance financial industry, so it refered to the argument of Brady and 
Cronin (2001), the interactive quality is measureed by three dimensions, including Attitude (At)、Behavior $(\mathrm{Be})$ 、 Professionality (Pr).

\section{The Promotional Activities (Pm)}

Promotional activities mean to provide an additional incentive or benefit through related promotional methods in order to stimulate consumers' purchasing behavior. The study emphasized on the bank specialists' repurchase intention, not on the customer as the research object. Therefore, "price promotion (PP)" and "non price promotion (NPP)", two dimentions were utilized to measure promotional activities of insurance company.

\section{Repurchase Intention (Ri)}

In this case, the sample was drawn from the financial specialists of banks which had contracted with the insurance company, and cited Chen Shufen's study (2002), who pointed out that the repurchase intention is the customers' willingness or motivation to buy the brand once again, and can be measured by whether bank specilists recommended life insurance company's products actively to friends or other people, and when other companies provide more preferential products, bank specilists won't be affected.

\section{RESEARCH METHOD AND HYPOTHESES}

\section{A. Research Framework}

Research framework is addressed as follows. "Fig. 1"

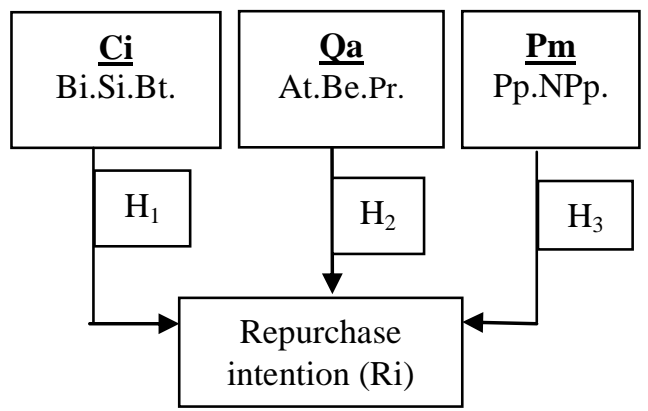

Fig. 1. Research framework

\section{B. Research Hypotheses}

Reliability is normally seen as the degree of consistency of a measure. Moser and Kalton (2001) stated, "A scale or test is reliable to the extent that repeat measurements made by it under constant conditions will give the same result" ( $p$. 353). In other words, the measuring procedure should yield consistent results on repeated tests, hence, the greater the degree of consistency and stability in an instrument, the greater is its reliability. The most popular test of inter-item consistency reliability is the Cronbach's coefficient alpha $(\alpha)$ (Cronbach, 1984), the value of $\alpha$ ranges from 0 to 1 . The nearer the value of $\alpha$ to 1 , the better the reliability is. If the value is low, either there are too few items or there is very little commonality among the items. For the early stages of any research, Hair et al. (1998) suggests that a coefficient of 0.7 or above is desirable. The internal consistency of the four categories in the questionnaire was estimated by SPSS v 19.0 for windows (SPSS, 2001) reliability test program, the Nunnally (1978) recommended standard (Cronbach Alpha $>0.70$ ) would act as the identification of composite reliabilities of this study (Hair et al., 1998). The research hypotheses are dressed as follows.

$\mathrm{H}_{1}$ : There is a significant correlation between $\mathrm{Ci}$ and $\mathrm{Ri}$. on $\mathrm{Ri}$

$\mathrm{H}_{1-1}$ : Brand identity $(\mathrm{Bi})$ has a significant positive effect $\mathrm{Ri}$

$\mathrm{H}_{1-2}$ : Store image ( $\mathrm{Si}$ ) has a significant positive effect on $\mathrm{Ri}$

$\mathrm{H}_{1-3}$ : Business trust $(\mathrm{Bt})$ has a ignificant positive effect on

$\mathrm{H}_{2}$ : There is a significant correlation between Qa and Ri.

$\mathrm{H}_{2-1}$ : Attitude(At) has a significant positive effect on $\mathrm{Ri}$ $\mathrm{R}$

$\mathrm{H}_{2-2}$ : Behaviour(Be) has a significant positive effect on

$\mathrm{H}_{2-3}$ : Pr has a significant positive effect on $\mathrm{Ri}$

$\mathrm{H}_{3}$ : There is a correlation between Pm and Ri.

$\mathrm{H}_{3-1}$ : Pp has a significant positive effect on $\mathrm{Ri}$

$\mathrm{H}_{3-2}$ : NPp has a significant positive effect on $\mathrm{Ri}$

\section{Questionnaire Survey and Data Collection}

380 questionnaires were administered, 353 (92.89\%) returned questionnaires. 23 of 335 questionnaires was not completed. Hence, the valid sample was 330 (86.84\%). The respondents' data (on the questionnaire) was divided into three parts: Part A, Part B and Part C. Part A consisted of the attributes of respondents including gender, bank district, numbers of years acting as a bank financial specilist (duration). While part B addressed the influencing factors ( $\mathrm{Ci}, \mathrm{Qa}, \mathrm{Pm})$, part $\mathrm{C}$ was relevant to the repurchase intention from the bank financial specilists'perspectives. The data of the three parts was entered into the software of SPSS v. 19.0. Reliability, T-test, one-way ANOVA, correlation analysis and regression analysis were utilized to analyze the collected data.

\section{RESEARCH RESULTS}

The following section will firstly present the percentage of respondents' demographic information, in terms of gender, bank district, numbers of years acting as a bank financial specilist. There were 98 male participants $(29.7 \%)$, and 232 female bank specilists $(70.3 \%)$, who took part in this program. 125 respondents' $(37.9 \%)$ working area is located in south of Taiwan. Of the 330 participants, there were 31 persons $(9.4 \%)$ working as a bank specilist for less than 3 years, 105 participants $(31.8 \%)$ who had worked for 5-10 years, 102 persons $(30.9 \%)$ who had worked for $11-15$ years, 92 respondents $(27.9 \%)$ who had worked more than 15 years. 


\section{A. Descriptive Statistics Analysis}

The mean values and standard deviations of the three influencing factors and repurchase intention (Ri) are recorded in "Table I".

TABLE I. DESCRIPTIVE STATISTICS OF VARIABLES

\begin{tabular}{|l|l|l|}
\hline & \multicolumn{1}{|c|}{ Mean $(\mathbf{M})$} & Standard Deviation(SD) \\
\hline Corporate Image & 5.193 & .298 \\
\hline Interactive quality & 5.233 & .487 \\
\hline Promotional activities & 4.828 & .379 \\
\hline Repurchase Intention & 4.967 & .467 \\
\hline
\end{tabular}

To compare the mean value of the influencing factos, interactive quality was ranked the highest; corporate Image was ranked the second, while the promotive activies was ranked the lowest. It figured out that bank financial specilists more emphasized on interactive quality with marketing managers of insurance company than the other two factors.

\section{B. Reliability Analysis}

The reliability of the three influencing factors and repurchase intention were examined using reliability test program of SPSS v. 19.0. All the values are more than .76, and meet the recommended standard Alpha $>.70$ (Hair et al. 1998).

\section{Independent Sample T-test}

Independent sample T-test was used to investigate the variance between different gender. The result of T-test showed that there was no statistically significant difference between males and females on the Corporate Image $(t=1.305$, $\mathrm{P}=.255)$, Interactive quality $(\mathrm{t}=1.270, \mathrm{P}=.206)$, promotional activities $(\mathrm{t}=.783, \mathrm{P}=.434)$ and Repurchase Intention $(\mathrm{t}=1.403, \mathrm{P}=.162)$.

\section{One-way Analysis of Variance(ANOVA)}

The ANOVA tests of significance will indicate whether there are statistically significant differences among the groups on a linear combination of the dependent variables. There are at least three statistics to choose from Wilk's Lamda, Hotelling's Trace and Pillai's Trace. Tabachnick and Fidell (1996) recommended Wilk's Lamda for general use, then Pillai's Trace is more robust, when the research with a small sample size, unequal $\mathrm{N}$ values, violation of assumption (p. 401). Pillai's Trace value was used to identify the significance in this study. A one-way analysis of variance between groups was performed to investigate bank specilists' characteristics differences in three influencing factors and repurchase intention. The rsults of one-way ANOVA will be addressed as follows.

1) Bank district: The result of one-way ANOVA showed that there was statistically significant difference between bank's District on the corporate image variable $(p=.043)$, the Sheffe test found that the mean value of corporate image in Taichung District was higher than the others. It indicated that Taichung District's consumers enphasized on corporate image more than the other districts' did when they purchased insurance products. However, there was no statistically significant difference between bank's District on the interactive quality $(p=.980)$ promotive activies $(\mathrm{p}=.806)$ and repurchase intention $(\mathrm{p}=.395)$. It meant that when customers purchase insurance pay more attention to the product itself.

2) Numbers of years acting as a bank financial specilist: The result of one-way ANOVA showed that there was no statistically significant difference between number of years acting as a bank financial specilist on the corporate image $(\mathrm{p}=.543)$, interactive quality $(\mathrm{p}=.657)$, promotion activies $(\mathrm{p}=.256)$ and repurchase intention $(\mathrm{p}=.302)$. It meant that when customers purchase insurance will pay more attention to the product itself rather than the seniority of bank specilists.

\section{E. Correlation Analysis}

Pearson's product-moment correlation method was performed before regression analysis, in order to examine the construct validity, and also to reveal the correlation within the three independent variables to check the presence of multicollinearity, which exists when the inter-correlation between independent variables exceed 0.8 (Berry \& Feldmann, 1985). The results indicated that there were significant correlation (correlation coefficient $>.3$ ). between three predictors and dependent variable were expected "Table II", However the three-predictor variables were independent (correlation coefficient $<.3$ ).

It can be seen that insurance company had a good corporate image $(\gamma=.562, \mathrm{p}<.001)$, interactive quality $(\gamma$ $=.486, \mathrm{p}<.001)$, promotive activies $(\gamma=.613, \mathrm{p}<.001)$ ended to achieve higher repurchase intention.

TABLE II. CORRELATION AMONG FOUR VARIABLES

\begin{tabular}{|l|l|l|l|l|}
\hline & \multicolumn{1}{|c|}{$\mathbf{C i}$} & \multicolumn{1}{|c|}{ Qa } & Pm & Ri \\
\hline $\mathrm{Ci}$ & 1 & & & \\
\hline $\mathrm{Qa}$ & $.133^{* *}$ & 1 & 1 & \\
\hline $\mathrm{Pm}$ & $.156^{* *}$ & $.191^{* *}$ & & \\
\hline $\mathrm{Ri}$ & $.562^{* *}$ & $.486^{* *}$ & $.613^{* *}$ & 1 \\
\hline
\end{tabular}

\section{F. Regression Analysis}

The aim of regression analysis is to summarise data as well as to quantify relationships among variables, expressed via an equation for predicting typical values of one variable given the value of other variables. Hanushek and Jackson (1977) suggested that stepwise regression is a useful procedure in determining most significantly related variables in explaining the behavior in question and this procedure allows the data "to tell the best model". Stevens (1996) noted that if an investigator wishes to determine whether some conceptually newer measures add anything to the dependent variable compared to older and more proven independent variables, it is appropriate to use stepwise regression. Thus, the stepwise regression analysis not only gives an indication of how comprehensive the effect of the independent variable is, but also details which aspect of a grossly defined variables have been differentially affected. There are two methods in the linear regression analysis; they are simple 
linear regression and multiple linear regression. When there is only one independent variable, the simple linear regression analysis would be selected, while there are more than two independent variables; the multiple linear regression would be employed. In the present study, there are six independent variables, thus, multiple linear regression method was utilized to analysis the collected data. SPSS can estimate the coefficient for multiple linear regression with more than two independent variables and list all of the possible regression models. SPSS provides three methods for controlling the entry or removal of independent variables from the regression model.

1) Corporate image and repurchase intention: The factor of corporate image was measured by three elements in terms of "brand identity", "the store image" and "corporate trust". The regression analysis results showed that three elements of corporate image explained $56.4 \%$ variance $\left(\mathrm{R}^{2}=0.564\right)$ of repurchase intention. The "brand identity" $\left(\beta=.276, P=.000^{* *}\right)$, the store image $(\beta=.376$, $\left.\mathrm{P}=.000^{* *}\right)$ and corporate trust $(\beta=.237, \mathrm{P}=.000 * *)$ had positive effect on repurchase intention, as shown in "Table III". Therefore $\mathrm{H}_{1}$ : There is a significant correlation between $\mathrm{Ci}$ and $\mathrm{Ri}$ is accepted, and $\mathrm{H}_{1-1}, \mathrm{H}_{1-2}$ and $\mathrm{H}_{1-3}$ are also accepted.

TABLE III. REGRESSION ANALYSIS OF CI AND Ri (N=330)

\begin{tabular}{|l|l|l|l|l|}
\hline \multirow{2}{*}{ Var. } & \multicolumn{3}{|c|}{ Repurchase intention } & \multirow{2}{*}{ VIF } \\
\cline { 2 - 4 } & $\beta$ & $\boldsymbol{t}$ & $\boldsymbol{p}$ & \\
\hline $\mathrm{Br}$ & .276 & 5.331 & $.000^{* *}$ & 1.783 \\
\hline $\mathrm{St}$ & .376 & 7.026 & $.000^{* *}$ & 1.897 \\
\hline $\mathrm{Bt}$ & .237 & 5.044 & $.000^{* *}$ & 1.489 \\
\hline $\mathrm{F}$ & 125.851 & \\
\hline Sig. & $.000^{* *}$ & \\
\hline $\mathrm{R}_{\text {Adj }}^{2}$ & .564 & ${ }^{\text {b. Note: } * * \mathrm{p}<0.01}$ \\
\hline
\end{tabular}

2) Interactive qualityand repurchase intention: The factor of interactive quality was measured by three elements in terms of "attitude", "behavior", "professionallity". The regression analysis results showed that three elements of interactive quality explained $18.2 \%$ variance $\left(\mathrm{R}^{2}=0.182\right)$ of repurchase intention. "Table IV"

TABLE IV. REGRESSION ANALYSIS OF QI AND RI (N=330)

\begin{tabular}{|l|l|l|l|l|}
\hline \multirow{2}{*}{ Var. } & \multicolumn{3}{|c|}{ Repurchase intention } & \multirow{2}{*}{ VIF } \\
\cline { 2 - 4 } & \multicolumn{1}{|c|}{$\beta$} & $\boldsymbol{t}$ & $\boldsymbol{p}$ & \\
\hline $\mathrm{At}$ & .156 & 2.200 & $0.02^{*}$ & 2.262 \\
\hline $\mathrm{Be}$ & .146 & 1.995 & $0.04^{*}$ & 1.453 \\
\hline $\mathrm{Pr}$ & .218 & 3.355 & $0.01^{*}$ & 1.962 \\
\hline $\mathrm{F}$ & 22.414 & \\
\hline Sig. & $.000^{* *}$ & \\
\hline $\mathrm{R}_{\text {Adj }}^{2}$ & .182 & \\
\hline
\end{tabular}

The "attitude" $(\beta=.156, \mathrm{P}=.02 *)$, behaviour $(\beta=.146$, $\left.\mathrm{P}=.04^{*}\right)$ and professionality $\left(\beta=.218, \mathrm{P}=.01^{*}\right)$ had positive effect on repurchase intention, as shown in Table 4.
Therefore $\mathrm{H}_{2}$ : There is a significant correlation between Qi and $\mathrm{Ri}$ is accepted, and $\mathrm{H}_{2-1}, \mathrm{H}_{2-2}$ and $\mathrm{H}_{2-3}$ are also accepted.

3) Promotion activies and repurchase intention: The factor of promotion activies was measured by two elements in terms of "price promotions" and "non-price promotions". The regression analysis results $\mathrm{s}$ howed that two elements ofpromotion activies explained $68.3 \%$ variance $\left(R^{2}=0.683\right)$ of repurchase intention. The "price promotions" $(\beta=.56$, $\left.\mathrm{P}=.00^{* *}\right)$ and non-price promotions $\left(\beta=.40, \mathrm{P}=.00^{* *}\right)$ had positive effect on repurchase intention, as shown in "Table V". Therefore $\mathrm{H}_{3}$ : There is a significant correlation between $\mathrm{Pm}$ and $\mathrm{Ri}$ is accepted, and $\mathrm{H}_{3-1}$ and $\mathrm{H}_{3-2}$ are also accepted.

TABLE V. REGRESSION ANALYSIS OF PM AND Ri (N=330)

\begin{tabular}{|l|l|l|l|l|}
\hline \multirow{2}{*}{ Var. } & \multicolumn{3}{|c|}{ Repurchase intention } & \multirow{2}{*}{ VIF } \\
\cline { 2 - 4 } & \multicolumn{2}{|c|}{$\beta$} & \multicolumn{1}{c|}{$\boldsymbol{p}$} & \\
\hline $\mathrm{Pp}$ & .56. & 6.683 & $.000^{* *}$ & 1.481 \\
\hline $\mathrm{Npp}$ & .400 & 7.493 & $.000^{* *}$ & 1.481 \\
\hline $\mathrm{F}$ & 116.851 & \\
\hline Sig. & $.000^{* *}$ & \\
\hline $\mathrm{R}_{\text {Adj }}^{2}$ & .683 & \multicolumn{2}{|c}{ d. Note: $* *{ }^{*}<0.01$} \\
\hline
\end{tabular}

\section{CONCLUSION}

\section{A. Study Findings}

There is a significant positive correlation between corporate images and repurchases intention, therefore insurance company could enhance its overall reputation to increase the repurchase intention of bank specilists by improving its social image, product quality and after service etc. Among three element of corporate image, brand identity had the highest correlation coefficient $(\gamma)$, this indicated that the better reputation of insurance company, the higher repurchase intention of bank specilists.

Similarly, a significant positive correlation exists between interactive quality and repurchases intention. The marketing managers are the representives of insurance company, they should have good service attitude in order to enhance the repurchase intention of bank specilists.

Again, there is a significant positive correlation between promotional activities and repurchases intention. The correlation coefficient $(\gamma)$ of promotion activies is higher than non-price promotion , therefore the repurchase intention could be enhenced through reducing price or increasing the quantity of products at the same price.

\section{B. Practical Contributions}

1) To provide a new interpretation model of repurchase intention: Many researches only focused on the impct of single variable on purchase intention, this study used an insurance company as sample, combined three variables in terms of corporate image, interactive quality and promotive activities together to explore the influencing extent of repurchase intention. The results showed that three factors had significant impact on repurchase intention synchronously, the finding provided the life insurance 
company with a new interpretation model in repurchased intention of bank specilists.

2) Provides marketing managers of the life insurance company with the important marketing reference: This study found that the interactive quality affect repurchase intention, and in which "attitude" was ranked the highest. It mean that the better service attitude of marketing manager, the higher repurchase intention of bank specilists. According to the results of this study, the sale promotion through bank channel of life insurance companies should be emphasized on the viewpoints of the bank specilists, at the mean time the marketing managers should interact with sincerity, amicability to enhance the repurchase intention of bank specilists. The results of this study also provide the life insurance company with important references of training.

\section{Suggestions}

Three suggestions are provided, firstly the insurance companies should strengthen its corporate image hence to enhance the reputation of product, it is helpful for bank specilist to sale insurance product smoothly. Secondly, the cultivation of excellent marketing manager, and raising the quality of the interaction to win bank specilists' goodwill and trust. Thirdly, Insurance companies should lunch price and non-price promotion irregularly, so as to promote the sales motivation of bank specialists, and further improve the sales performance.

\section{Limitations}

The limitations of the study can be divided into three areas. The first set concerns potential bias in the sample population and sample size. The second set concerns research design, research methods and data analysis technique. Another shortcoming of this research involves the measures used.

\section{REFERENCES}

[1] Allison, E. H., \& Philip, J. R. (2004). The effect of corporate image in the formation of customer loyalty: An Australian replication. Australasian Marketing Journal, 12(3), 88-96.

[2] Andreassen, T. W., \& Lindestad, B. (1998). The effect of corporate image in the formation of customer loyalty. Journal of Service Research, 1(1), 82-92.

[3] Belch, G., \& Belch, M. (2003). Advertising and promotion: An integrated marketing communications perspective. (6th Ed.). Boston, MA: Irwin/McGraw-Hill.

[4] Brady, M. K., \& Cronin, J. J. (2001). Customer orientation: Effects on customer service perceptions and outcome behaviors. Journal of Service Research, 3(3), 241-251.

[5] Nguyen, N., \& Leblanc, G. (2001). Corporate image and corporate reputation in customers' retention decisions in services. Journal of Retailing and Consumer Services, 8(4), 227-236. 